\title{
LEO SCHIBLI
}

\section{(7 DE ENERO DE 1958 - 8 DE OCTUBRE DE 2004)}

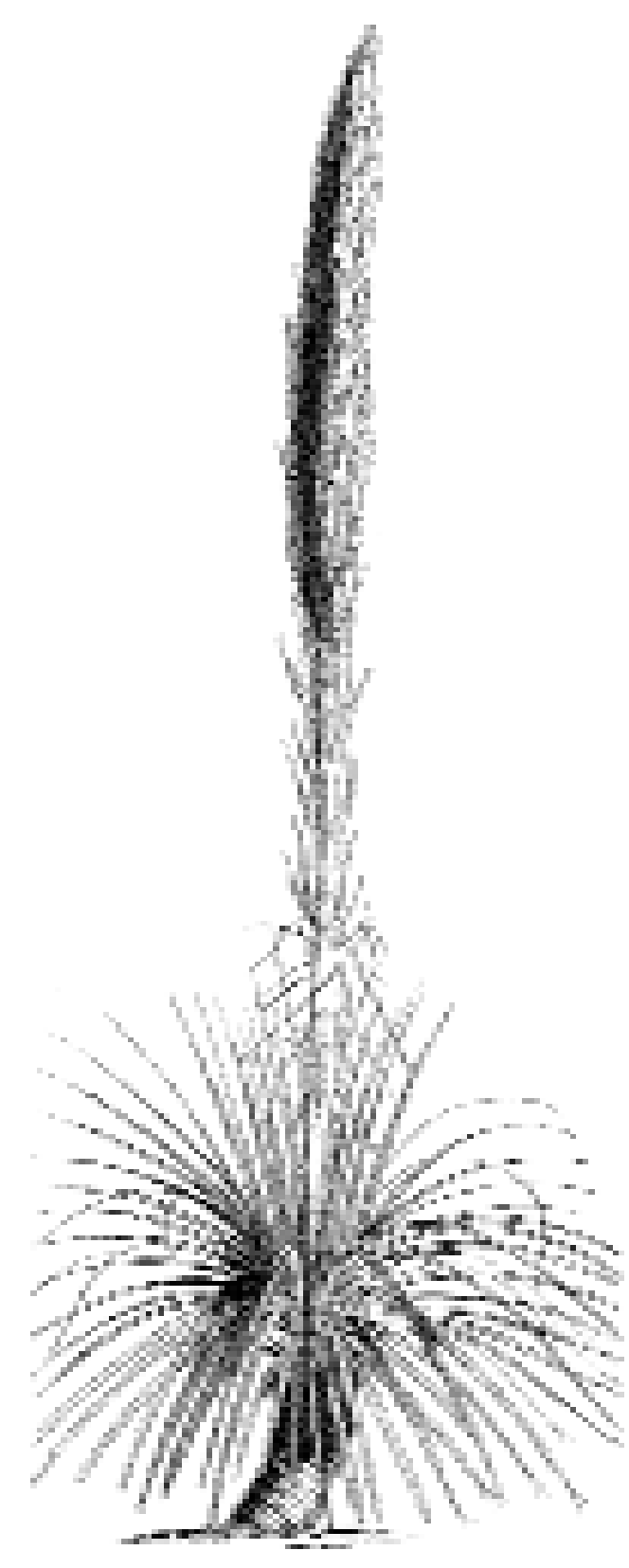

eo Schibli nació en Zurich, Suiza, el 7 de enero de 1958, en donde pasó su niñez — y adolescencia. Viajero incansable, muy pronto Suiza resultó ser pequeña para un internacionalista como él. Estudió en el Politécnico de Suiza una carrera técnica en química. Trabajó en varias industrias suizas, pero al mismo tiempo viajó por diversos sitios del mundo. En 1982 vino por primera vez a México, tierra a la que nunca pudo dejar.

Leo estudió español en Cuernavaca y muy pronto se dedicó a crear sus propias palabras en este idioma. Posteriormente viajó algunos meses por Centroamérica y vivió en Nicaragua casi un año, apoyando la reconstrucción de escuelas y hospitales. Fue en mayo de 1988 cuando llegó a Oaxaca, y en ese entonces apoyó diversas actividades en el Centro de Graduados del Instituto Tecnológico de Oaxaca, sin percibir ningún salario y sólo por el afán de ayudar. Más tarde fue uno de los socios fundadores de la Sociedad para el Estudio de los Recursos Bióticos de Oaxaca, Asociación Civil (SERBO, A.C.). Desde esta organización, Leo impulsó en Oaxaca el uso de sensores remotos y sistemas de información geográfica para cartografiar y monitorear la distribución y condición de los bosques y selvas del estado.

La pasión de Leo fueron los mapas. Lástimamente, como diría él, todavía hay muy poca cultura cartográfica en México y pocos llegaron a apreciar la calidad de la cartografía que él sabía hacer. Con sus mapas Leo apoyó diversos movimientos ambientalistas en Oaxaca, principalmente en la zona de Chimalapas, región para la cual elaboró al menos 50 mapas de diversos temas. En 1998, junto con los equipos de SEMARNAP y SEDENA, produjo la cartografía que habría de apoyar el control de incendios que devastaron más de 200,000 ha de esta importante región. Con sus vastos conocimientos sobre la fisiografía de Oaxaca, generó información muy importante sobre los bosques mesófilos y mesofilíticos (palabra acuñada también por Leo) del estado, principalmente de Sierra Norte y Chimalapas. Sus mapas apoyaron a más de 50 proyectos ejecutados en SERBO.

Leo participó en diversos foros nacionales e internacionales sobre la definición de áreas prioritarias para la conservación en México. A partir de 1994 asistió como ponente a los Congresos Mexicanos de Botánica. Una de sus metas era que más y más gente apreciara la importancia de la información de campo georeferenciada, para lo cual capacitó a un gran número de personas en el manejo de posicionadores geográficos y apoyó a varias comunidades forestales en el desarrollo de sistemas de 
información geográfica, pues estaba convencido de que estos sistemas impulsarían el desarrollo forestal en Oaxaca y fortalecerían el trabajo comunal.

Naturalista incansable, Leo nunca dejó de sorprenderse ante las maravillas naturales de Oaxaca, y ello hizo de él un defensor apasionado de la riqueza biológica de su estado adoptivo. Sin ser biólogo ni botánico, pero amante de plantas y animales, mantenía la capacidad de asombro por las diversas formas, colores y aromas que encontraba en el campo.

Leo murió el 8 de octubre de 2004. Con su fallecimiento se llevó consigo un gran acervo de experiencias y saberes, resultado de un trabajo incansable y autodidacta que no conocía de horarios y, algunas veces, sin remuneración salarial. Sin embargo, lo que más se extrañará de él será su manera de defender sus puntos de vista, su empecinamiento por hacer ver lo que estamos perdiendo en Oaxaca y su espíritu siempre libre.

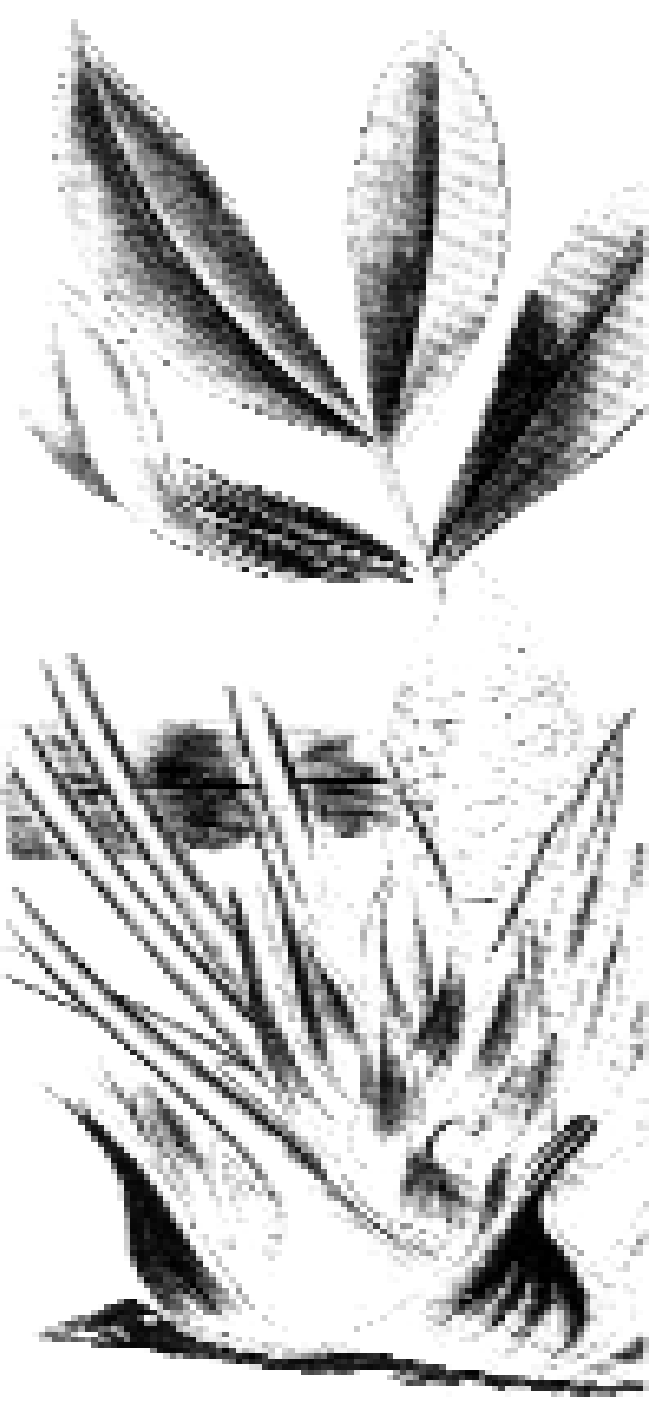

Silvia H. Salas-Morales

Sociedad para el Estudio de los Recursos Bióticos de Oaxaca, A.C. 